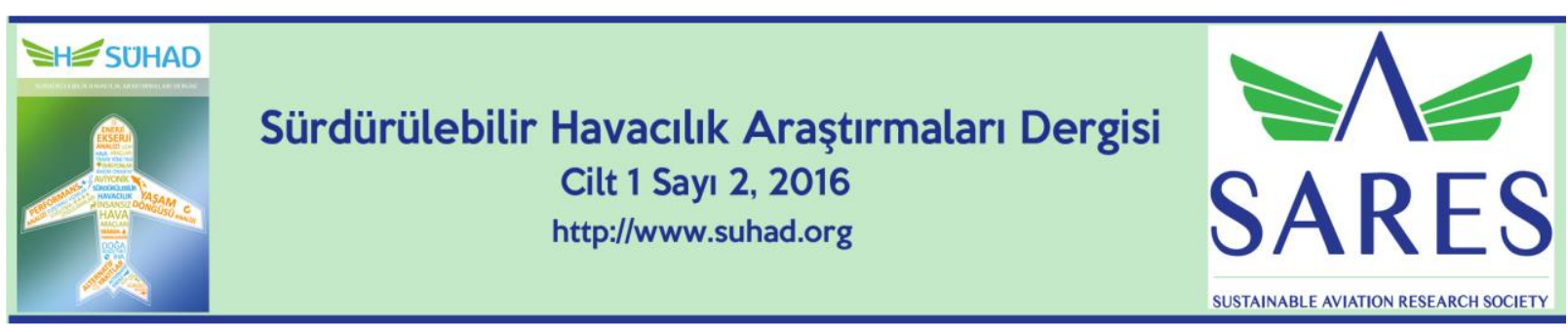

\title{
YÜKSEK HIZLI SAHTE HEDEF İHA TASARIMI
}

\author{
Umut BAYKARA ${ }^{1}$, Nafiz ALEMDAROĞLU² \\ ${ }^{1}$ Umut Baykara, Orta Doğu Teknik Üniversitesi, Havacılık ve Uzay Mühendisliği, umut.baykara@metu.edu.tr \\ ${ }^{2}$ Nafiz Alemdaroğlu, Atılım Üniversitesi, Uçak Gövde Motor Bakım Bölümü, nafiz.alemdaroglu@atilim.edu.tr \\ DOI: 10.23890/SUHAD.2016.0111
}

\section{ÖZET}

Bu çalışma, yüksek hızlı hedef İHA tasarımını, HAD aerodinamik analizini ve en iyi aerodinamik performansı veren yüksek hızlı İHA'nın seçilmesini içermektedir. Temel gereksinimler geçmiş tasarımlardan elde edilen tecrübelere dayanmaktadır. Gereksinimler şunları içermektedir. $15000 \mathrm{ft}$ yüksekliğe çıkabilme, 450 knot hıza çıkabilme, en az 1 saat dayanım süresine sahip olma. Hedef İHA pnömatik mancınık tarafından firlatılıp, paraşüt sistemi ile inecektir. İleri derecede çevik olacak bu uçak, yüksek manevra kabiliyetine sahip olacaktır. Devaml $6 \mathrm{~g}$ ve anlık $9 \mathrm{~g}$ yük faktörü kabiliyetine sahip olması amaçlanmıştır. Gerekli görülen yük kapasitesi $10 \mathrm{~kg}$ olarak ayarlanmıştır ve duman atıcısı, pasif radar iz arttırıcı ve karşı tedbir atım sistemi içerir. Bu çalışmanın amacı akranları ile rekabet edebilecek düzeyde optimize edilmiş bir yüksek hızlı İHA tasarlamak olduğu için, yeni jenerasyon hesaplamalı akışkanlar dinamiği yazılımı kullanılacak ve en uygun aerodinamik performansı gösteren yüksek hızlı hedef İHA konfigürasyonu seçilecektir. Ana tasarım ve diğer konfigürasyonlar farklı kanat ve kuyruk geometrik şekillerinde oluşturulmuştur. Bütün geometriler, bilgisayar destekli tasarım yazılımında oluşturulmuş ve farklı akış rejimlerinde analiz edilmiştir. Son olarak, farklı dizayn ve performans kriterlerine göre konfigürasyon seçimi yapılmıştır.

Anahtar Kelimeler: Hedef, İHA, Tasarım, HAD, Optimizasyon

\section{DESIGN OF A HIGH SPEED DECOY UAV}

\begin{abstract}
This study consists of design, CFD aerodynamic analysis and optimized selection of a high-speed decoy UAV. The mission requirements for the high-speed decoy are based upon the previous experiences in literature. The requirements are specified as: Maximum altitude of $15000 \mathrm{ft}$, maximum speed of 450 knots and an endurance of at least 1 hour. The decoy UAV is launched from a pneumatic catapult and lands via a parachute system. It is a highly agile aircraft having a very high maneuverability capability. The aircraft has a $6 \mathrm{~g}$ sustained and $9 \mathrm{~g}$ instantaneous load factor. Required payload capacity is set to be as $22 \mathrm{lbs}$, consisting of a smoke dispenser, a passive radar cross section augmenter (luneberg lens), a chaff and IR dispenser and a miss distance indicator. Since, the aim of this study is to design an optimized high-speed decoy that surpasses its predecessors, a new generation CFD tool is used to achieve the high speed decoy configuration which gives the best aerodynamic performance. Baseline design and other configurations were created according to their vertical wing and tail geometry designs. All models were created in CAD environment and analyzed for different flow regimes and envelopes. Finally, configuration is selected considering various design and performance criteria.
\end{abstract}

Keywords: Decoy, UAV, Design, CFD, Optimization 


\section{GIRIS}

İHA'lar boyut, menzil/irtifa ve fonksiyonlarına göre sınıflandırılırlar. İHA fonksiyonları keşif, saldırı, lojistik, sahte hedef ve ar-ge olarak bilinmektedir. Sahte hedef İHA'lar yeni silah sistemlerinin test edilebilmesi için düşman uçağını simülasyonunu yapar. Bu İHA çeşidi, iz duman atıcısı, karşı tedbir atım sistemi, luneberg lensleri ve kaçırma mesafe ölçeri gibi kendine özel faydalı yükler içerir. Sahte hedef İHA'lar da üç formda kategorize edilir, bunlar: Düşük Hızlı, Yüksek Hızlı ve insanlı hava araçlarının çevrilmesi ile oluşturulan sahte hedeflerdir. $\mathrm{Bu}$ çalışmanın amacı, geçmiş tecrübelerden faydalanılarak yüksek hızlı bir Sahte Hedef İHA tasarımı yapmaktır. Geçmiş tecrübelerden faydalanabilmek için öncelikle literatür araştırması yapılmıştır. Literatür araştırmasında Şimşek (TUSAŞ, 2016), Meggit Banshee Twinjet (Meggit Defence, 2016), Yperion (BSK Defence, 2016), Nemisis[BSK Defence,2016], Firejet (Composite Engineering, 2016), BQM-167A (Composite Engineering, 2016) gibi sahte hedef İHA'ların ölçüleri, faydalı yük kapasiteleri, motor güçleri ve çıkabildikleri maksimum hız ve irtifaları incelenmiştir.

\section{YÖNTEM}

\subsection{Gereksinimlerin Belirlenmesi ve Görev} Profili

Uçak dizaynı aerodinamik, yapısal, kontrol ve itki gibi birçok alanın kombinasyonundan oluşmaktadır. Uçak dizayn süreci uçağın gerekliliklerinin belirlenmesi ile başlar. Uçağın gereksinimleri dizayn süreci boyunca değişebilir (Raymer, 2012). Literatür araştırması sonrasında tasarlanmak istenen uçağın gereksinimleri tablo 1 de verilmiştir.

Tablo 1: Yüksek Hızlı Hedef İHA Gereksinimleri

\begin{tabular}{|l|l|}
\hline Faydalı yük kapasitesi & $22 \mathrm{lbs} / 10 \mathrm{~kg}$ \\
\hline Maksimum hız & $450 \mathrm{KTS} / 231 \mathrm{~m} / \mathrm{s}$ \\
\hline Dayanım süresi & $1 \mathrm{saat}$ \\
\hline Maksimum irtifa & $15000 \mathrm{ft}$ \\
\hline Manevra Kabiliyeti & $\begin{array}{l}9 \mathrm{~g} \mathrm{anlık} \mathrm{6g} \mathrm{devamlı} \\
\text { yük faktörü }\end{array}$ \\
\hline Kalkış ve İniş & $\begin{array}{l}\text { Pnömatik Mancınık / } \\
\text { Paraşüt }\end{array}$ \\
\hline Uçuş Menzili & $100 \mathrm{~km}$ \\
\hline
\end{tabular}

Dizayn adımlarının dizayn sırasında kolayca izlenebilmesi için dizayn metodu akış tablosu hazırlanmıştır.

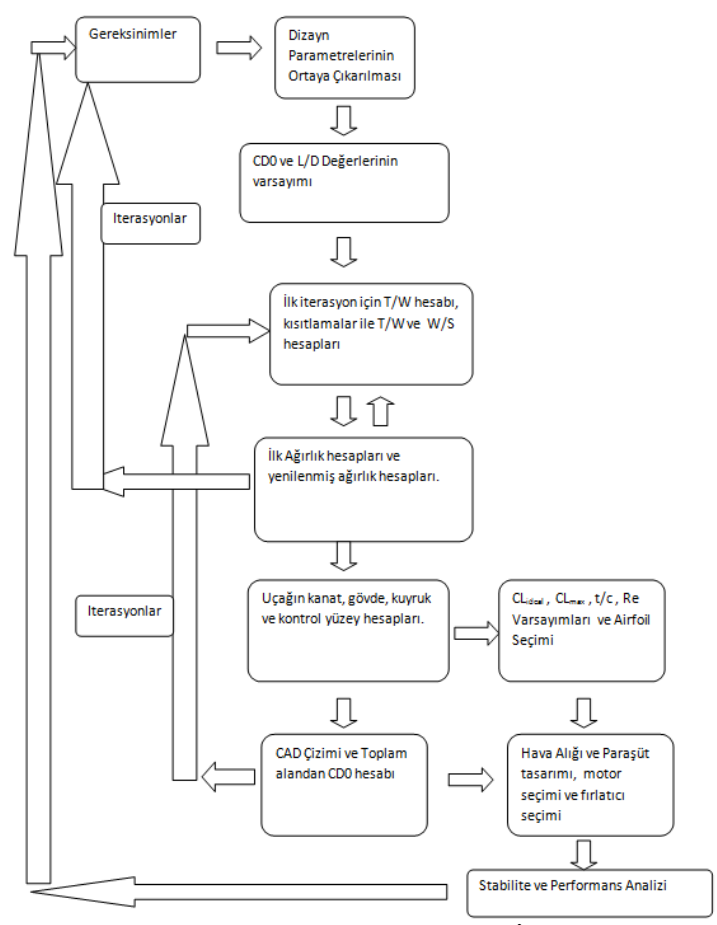

Şekil 1: Yüksek Hizlı Hedef İHA Dizayn Metodolojisi

Hazırlanan gereksinimlere uygun olarak tasarlanacak Sahte Hedef İHA için görev profili oluşturuldu. Görev profilindeki her bir görev bölümüne uygun olarak uçağın ağırlık hesapları ve boyutlandırılması yapıldı.

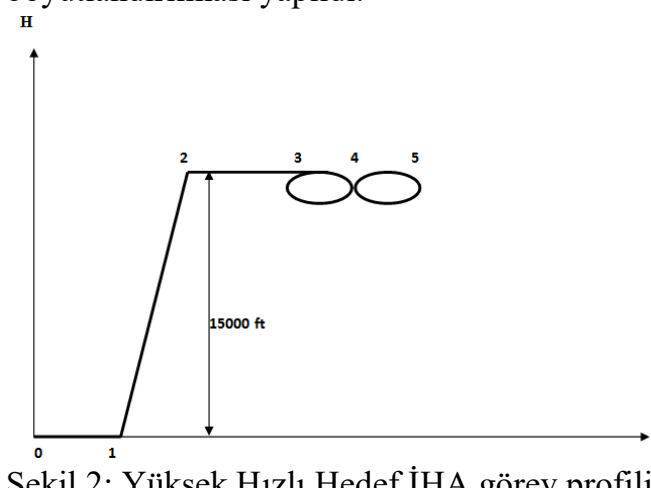

Şekil 2: Yüksek Hızlı Hedef İHA görev profili

Tasarlanacak Hedef İHA'nın görev profili açıklaması aşağıdadır;

0 - 1: Deniz seviyesinde pnömatik mancınıkla kalkış

1 - 2: $15.000 \mathrm{ft}$ yüksekliğe tırmanış

2 - 3: $15.000 \mathrm{ft}$ yükseklikte kalkış bölgesinden hedef bölgesine $100 \mathrm{~km}$ seyir

3 - 4: $15.000 \mathrm{ft}$ yükseklikte hedef bölgesinde 50 dakika oyalanma

4 - 5: Hedef bölgesinde10 dakika manevra gerçekleştirme 


\subsection{Hedef İHA Tasarımı}

İlk aşamada görev bölümlerine uygun olarak Hedef İHA'nın yaktı̆̆g yakıt hesaplanmış ve uçağın ağırlı̆̆ı hesaplanmıştır. Uçağın ağırlık analizi tamamlandıktan sonra uçağın gövde, kanat ve kuyruk boyutları ortaya çıkarılmıştır. Uçağın dikey kanat pozisyonu olarak orta-kanat seçilmiştir. Orta kanat şeklinin, hem yüksek-kanat hem alçak-kanat şekil özelliklerine sahip olacağ hem de gövde ile olan etkileșiminin ve bunun sağladığı sürükleme katsayısının minimum olacağı düşünülmüştür. Uçağın yatay kuyruk pozisyonu olarak T-kuyruk seçilmiştir, T-kuyruğun tasarımı basittir ve düz uçuş sırasında yatay kuyruğun, kanadın ve jet motorunun etkisinde kalmama avantajina sahiptir.

Airfoil seçimi aşamasından önce, uçak için gerekli olan Mach Sayısı(M), Reynolds Sayısı(Re), Dizayn kaldırma katsayısı( $\mathrm{C}_{\mathrm{LDesign}}$ ), maksimum kaldırma katsayısı $\left(\mathrm{C}_{\mathrm{Lmax}}\right)$ hesaplanmıştır. Hesapları takiben XFLR5 yazılımı kullanılarak farklı airfoil çeşitleri karşılaştırılmıştır. Airfoiller arasından en düşük sürükleme katsayısı $\mathrm{C}_{\mathrm{d}(\text { min), en }}$ yüksek $C_{1} / C_{d}$, en yüksek stall açısı $\left(\alpha_{\text {stall }}\right)$, en yüksek maksimum kaldırma katsayısı $\left(\mathrm{C}_{\mathrm{Lmax}}\right)$, uygun dizayn kaldırma katsayısı $\left(\mathrm{C}_{\text {LDesign }}\right)$ ve uçağın uçacağı mach sayısı için uygun $\mathrm{t} / \mathrm{c}$ oranı özelliğine sahip olan airfoil seçilmiştir. Uçağın yatay ve dikey kuyrukları için simetrik airfoil seçilmesi uygun görülmüştür.

Uçağın hava alığı, gövdenin altında pitot tipi olarak seçilmiştir. Bu sayede yüksek hücum açılarında uçağın uçabilecek kadar hava alması amaçlanmıştır. Sınır katmanı oluşumunun uçağa giren hava akışını engellememesi için uçağın gövdesi ile hava alığı arasına bir miktar boşluk bırakılmıştır. Uçağın hava alı̆̆ı aşağıdaki şekilde gösterilmiştir.

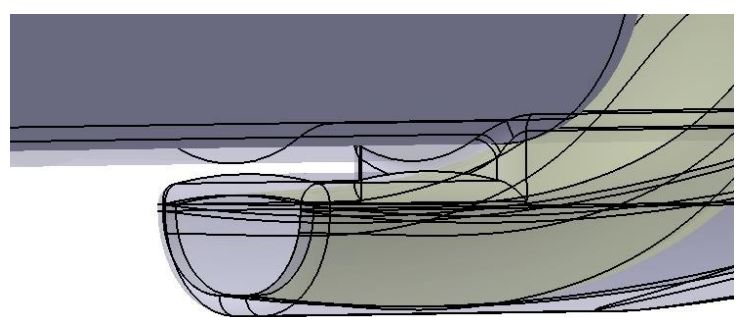

Şekil 3: Hedef uçağın Hava Alığı

Uçağın maksimum hızına ulaşabilmesi için yeterli itiş gücünü sağlayabilen motorun seçimi gerekmektedir. Düşük ağırlığı ve akranlarına oranla daha yüksek itiş gücü kapasitesi ve uçağa gerekli itiş gücünü verebilecek bir motor olan NIKE turbo jet motoru hedef uçak için seçilmiştir. NIKE turbo jet motoru alttaki şekilde verilmiştir.

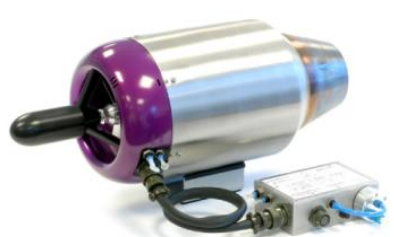

Şekil 4: Nike Turbojet Motoru (AMT Nederlands, 2012)

Nike Turbojet motoru Catia-v5 yazılımında teknik resminden birebir çizilmiş ve modele eklenmiştir.

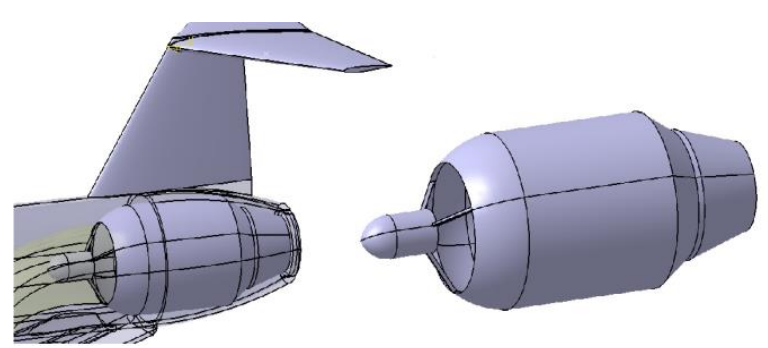

Şekil 5: Nike Turbo jet Motorunun CAD Çizimi ve Modele Entegrasyonu

Tablo 2: Yüksek Hızlı Hedef İHA Geometrik Özellikleri

\begin{tabular}{|c|c|}
\hline Uzunluk & $2,75 \mathrm{~m}$ \\
\hline Gövde Çap1 & $0,25 \mathrm{~m}$ \\
\hline Kanat Görünüş oranı & 5 \\
\hline Kanat Açılı̆̆1 & $1,94 \mathrm{~m}$ \\
\hline $\begin{array}{c}\text { Maksimum kalkış } \\
\text { Ağırlığ } 1\end{array}$ & $85 \mathrm{~kg}$ \\
\hline
\end{tabular}

Tablo 3: Yüksek Hızlı Hedef İHA Uçuş Hızları

\begin{tabular}{|c|c|}
\hline $\mathrm{V}_{\text {stall }}(\mathrm{ft} / \mathrm{s})(\mathrm{m} / \mathrm{s})$ & $143,46 / 43,5$ \\
\hline $\mathrm{V}_{\text {loiter }}(\mathrm{ft} / \mathrm{s})(\mathrm{m} / \mathrm{s})$ & $238,44 / 72,7$ \\
\hline $\mathrm{V}_{\text {cruise }}(\mathrm{ft} / \mathrm{s})(\mathrm{m} / \mathrm{s})$ & $323,232 / 98,5$ \\
\hline $\mathrm{V}_{\text {max }}(\mathrm{ft} / \mathrm{s})(\mathrm{m} / \mathrm{s})$ & $759,5 / 231,5$ \\
\hline $\mathrm{V}_{\text {combat }}(\mathrm{ft} / \mathrm{s})(\mathrm{m} / \mathrm{s})$ & $452 / 137,8$ \\
\hline
\end{tabular}

Tasarlanan İHA'nın temel tasarımının Catia-v5 yazılımında çizimi aşağıdaki şekilde verilmiştir.

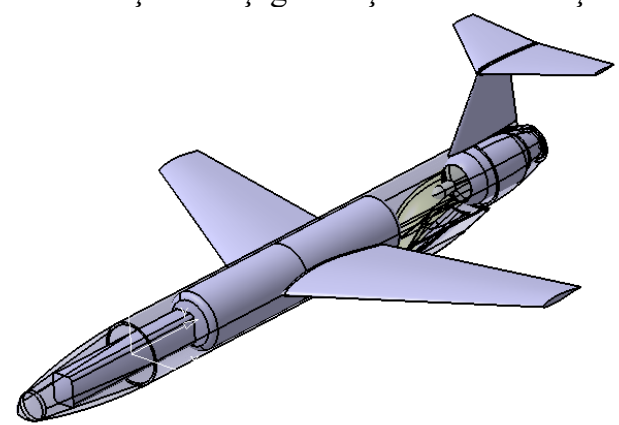

Şekil 6: Yüksek Hızlı Hedef İHA Temel Tasarım CAD Çizimi

\subsection{Hedef İHA Konfigürasyonları}


Hedef İHA için orta-kanat ve T-kuyruk seçilmişti. Ancak, T-kuyruk dikey kuyruğun kendisini taşımasını gerektirdiği için dikey kuyruğun yapısal olarak daha sağlam ve ağır olmasını gerektirir. Tkuyruğun önemli bir dezavantajı daha vardır. Derin stol adı verilen bu durum, yüksek hücum açılarında kuyruktaki kontrol yüzeyi olan elevatorun kanadın etkisinde kalması ile oluşur. Elevator kanadın etkisinde kaldığı için uçak yönlendirilemez ve bu durum uçağın düşmesine bile neden olabilmektedir. Derin stall durumu aşağıdaki şekilde gösterilmiştir.

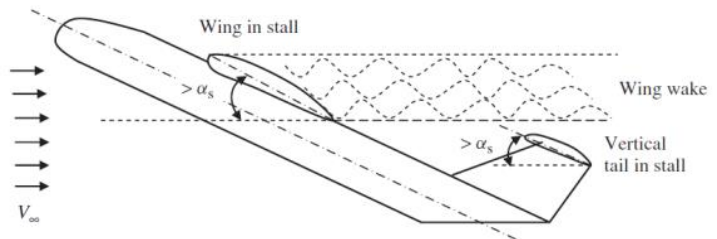

Şekil 7: T-kuyruk Şeklindeki Derin Stall Durumu (Sadraey, 2013)

Ana tasarım bitirildikten sonra kanadın ve kuyruğun dikey pozisyonlarının değiştirildiği diğer konfigürasyonların da tasarımı yapıldı. $\mathrm{Bu}$ diğer tasarımları yapmanın amacı, farklı kanat ve kuyruk dikey pozisyonlarının değiştirildiğinde uçağın verdiği aerodinamik performansının nasıl değiştiğini gözlemlemektir. Uçağın kanadının kuyruğu nasıl etkilediğini gözlemleyip optimum kanat-kuyruk dikey pozisyonlarını yakalamak. Bunun için Hesaplamalı Akışkanlar Dinamiği (HAD) analizleri kullanılmıştır.

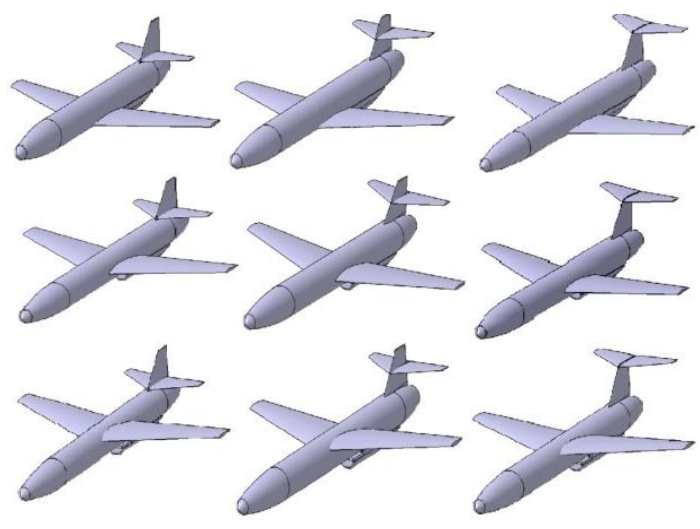

Şekil 8: Yüksek Hızlı Hedef Uçak Konfigürasyon Matrisi

\subsection{Seyir Hızı HAD Analizleri ve Konfigürasyon Seçimi}

Hesaplamalı Akışkanlar Dinamiği(HAD) araçları, uçağın istenilen atmosfer koşullarında ve istenilen hızlarda simüle etmeye olanak tanır. Son günlerde, HAD simülasyonları ticari/askeri uçakların ve İHA'ların optimum şekilde tasarlanmasında önemli rol oynamaktadır. FloEFD, Mentor Graphics tarafından geliştirilen ve birçok alanda kendini kanıtlamış modern HAD yazılımlarından biridir. Catia-v5, Solidworks, Creo ve Siemens NX gibi modern CAD yazılımlarına gömülü olarak çalışan FloEFD, bu sayede zaman tasarrufu sağlamaktadır. Bu çalışmada Catia-v5 içerisine gömülü FloEFD-v14.2 kullanılmıştır.

HAD analizinin metodolojisi sonraki şekilde gösterilmektedir:

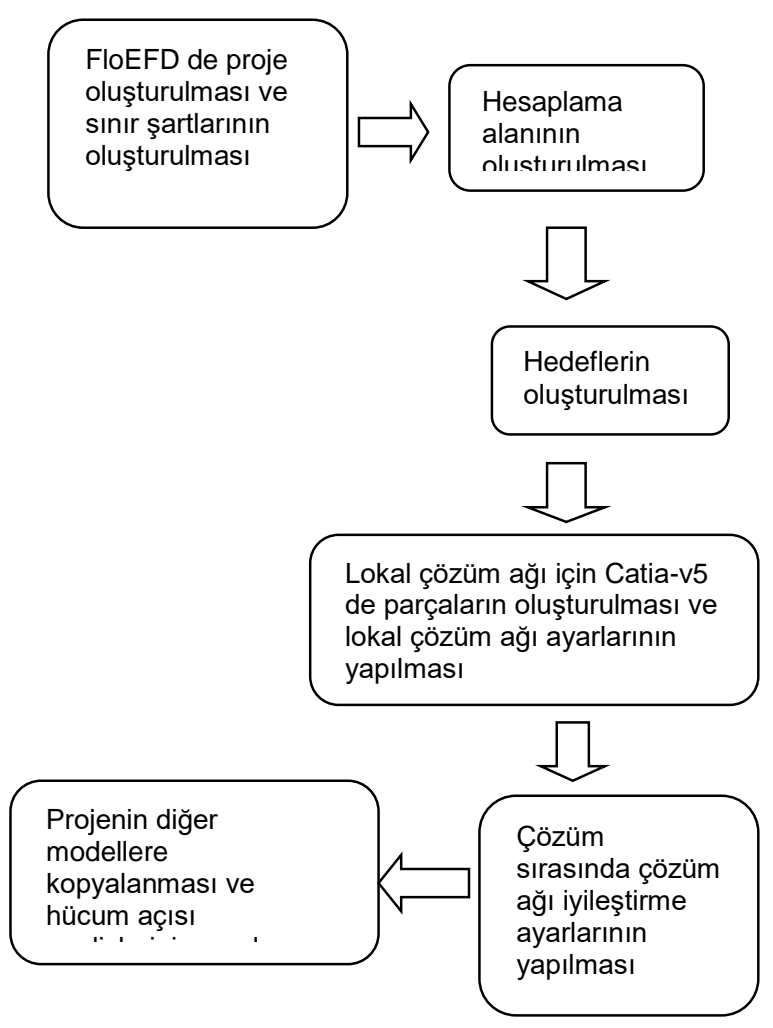

Şekil 9: HAD Analizi Methodolojisi

Tablo 4: Oluşturulan Proje Koşulları ve Sınır Şartlar1

\section{UYGULAMALAR}




\begin{tabular}{|c|c|}
\hline Hava Özkütlesi & $0,771 \mathrm{~kg} / \mathrm{m}^{3}(15000 \mathrm{ft})$ \\
\hline Dış Basınç & $57205 \mathrm{~Pa} \quad(15000 \mathrm{ft})$ \\
\hline Analiz Tipi & Diş \\
\hline $\begin{array}{c}\text { Türbülans } \\
\text { Parametresi }\end{array}$ & $\begin{array}{c}\text { Yoğunluk ve Uzunluk } \\
(\% 0,1) \quad(0,00625 \mathrm{~m}) \\
\text { (Modelin boyutlarına göre } \\
\text { FloEFD tarafindan otomatik } \\
\text { hesaplanmıstır) }\end{array}$ \\
\hline $\begin{array}{l}\text { Uzunlamasına } \\
\text { Düzlem }\end{array}$ & XY Düzlemi \\
\hline $\begin{array}{l}\text { Uzunlamasina } \\
\text { Eksen }\end{array}$ & Y Koordinatı \\
\hline $\begin{array}{l}\text { Akış Tipi } \\
\text { Opsiyonu }\end{array}$ & $\begin{array}{l}\text { Laminar ve Turbulent } \\
\text { (Akışın tipi ve sıkıştırılabilir } \\
\text { olup olmadığ } 1 \text { FloEFD } \\
\text { tarafından otomatik } \\
\text { hesaplanır) }\end{array}$ \\
\hline
\end{tabular}

Hesaplama Alanı

$\mathrm{X}=0 / 10 \mathrm{~m}$

$\mathrm{Y}=23 \mathrm{~m} /-10 \mathrm{~m}$

yönü daha uzun)

$\mathrm{Z}=10 \mathrm{~m} /-10 \mathrm{~m}$
Toplam 20m (simetri) Toplam 33m (Akıntı

Toplam 20m

FloEFD yazılımında istenen hedefi tanımlamak gereklidir. FloEFD de beş farklı hedef çeşidi vardır bunlar, nokta hedefleri, düzlem hedefleri, hacim hedefleri, tüm alanı kapsayan genel hedefler ve denklem hedefleri. Hedefler (Mentor Graphics, 2010) a göre belirlenmiştir. Hesaplama alanında bulunan $(0,-9,8,0)$ bölgesine bir nokta atanmıştır, bu noktaya akışın hızı, Y ve Z bileşen hızları ve yoğunluğu tanımlanmıştır. Hesaplama alanının içine $\mathrm{Y}$ ve $\mathrm{Z}$ yönüne doğru toplam kuvvet genel hedefi tanımlanmıştır. Genel ve nokta hedefleri tanımlandıktan sonra aşağıdaki denklem hedefleri yazılıma tanımlanmıştır. (Mentor Graphics, 2010)

$$
\begin{aligned}
& \text { Dikey Kuvvet KatsayısI }=\frac{\operatorname{GGForce}(Z)}{\frac{1}{2} *(P G \text { Density }(\text { fluid })) *(P G \text { Velocity })^{2}{ }^{*}}
\end{aligned}
$$

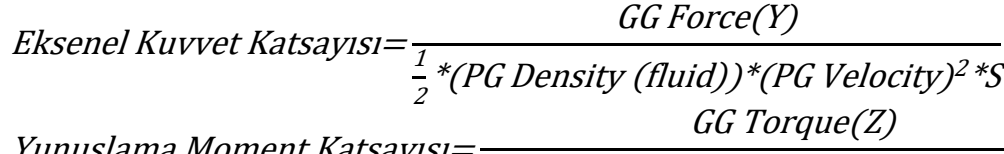

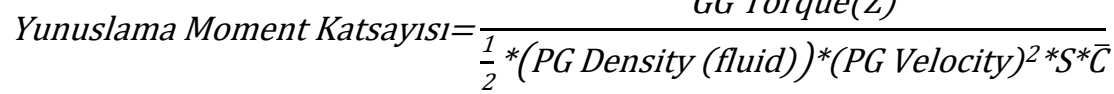

$$
\begin{aligned}
& \text { Kaldırma Katsayısı }=\left(\text { Dikey Kuvvet Katsayısı } * \frac{P G \operatorname{Velocity}(Y)}{P G \text { Velocity }}\right) \\
& -\left(\text { Eksenel Kuvvet Katsayısı } * \frac{P G \text { Velocity }(Z)}{P G \text { Velocity }}\right)
\end{aligned}
$$$$
\text { Sürükleme Katsayısı }=\left(\text { Eksenel Kuvvet Katsayısı } * \frac{P G \text { Velocity }(Y)}{P G \text { Velocity }}\right)+
$$$$
\text { (Dikey Kuvvet KatsayısI } \left.* \frac{P G \text { Velocity }(Z)}{P G \text { Velocity }}\right)
$$

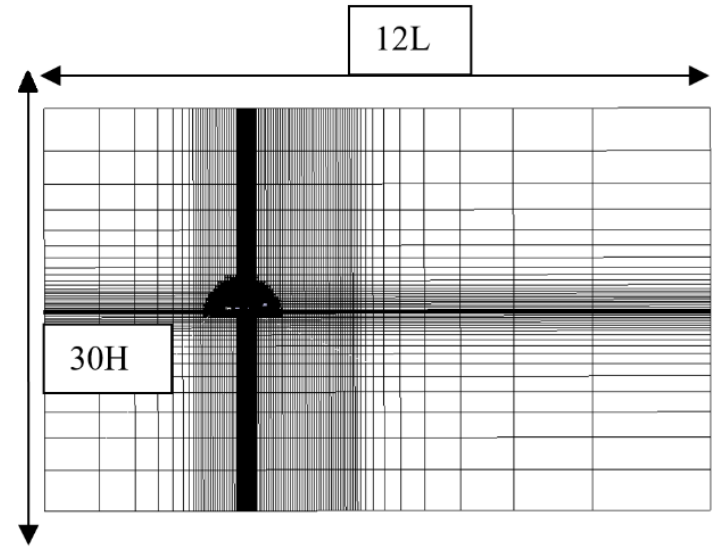

Şekil 11: İHA Hesaplama alanı ilk çözüm ağı
Hesaplama alanı için ilk çözüm ağı kontrol düzlemleri kullanılarak oluşturulmuştur. İlk mesh"NASA Common Research Model(CRM)" baz alınarak oluşturulmuştur (Mentor Graphics, 2014). Kontrol düzlem yerleri yüksek hızlı İHA model boyutlarına göre kalibre edilmiştir. İlk çözüm ağı yapısı aşağıdaki şekilde verilmiştir. Şekilde siyah görünen dikey çizgi, kanadın bulunduğu kontrol düzlem bölgesidir.

Yüksek Hızlı Hedef uçak geometrisine genel çözüm ağının yanı sıra üç farklı bölgeye lokal çözüm ağı atılmıştır. Bu bölgelerde çözüm ağı atılmış ve bu bölgeleri yazılımın katı olarak algılamaması sağlanmıştır. Bu bölgeler:

1- Diş yarı küre lokal çözüm ağ

2- Kanat lokal çözüm ağ 1

3- Kuyruk lokal çözüm ağı 

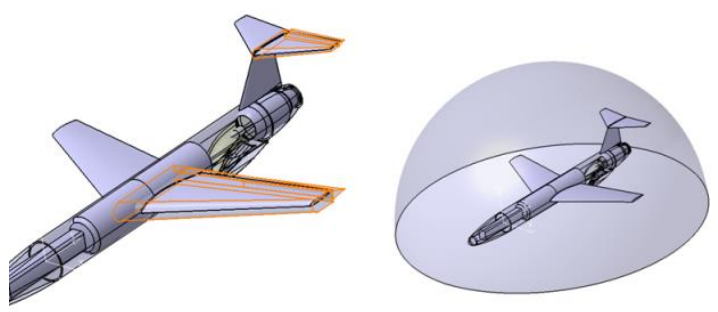

Şekil 12: Kanat, kuyruk ve yarıküre lokal ilk çözüm ağ1 bölgeleri

Optimum çözüm ağına ulaşabilmek için, kanat ve kuyruk lokal çözüm ağı için çözüm ağı iyileştirme ayarı 4. Seviye ve yarı küre için 1. Seviye olarak ayarlanmıştır. Kanatlardaki ilk çözüm ağı Alttaki şekilde gösterilmektedir.

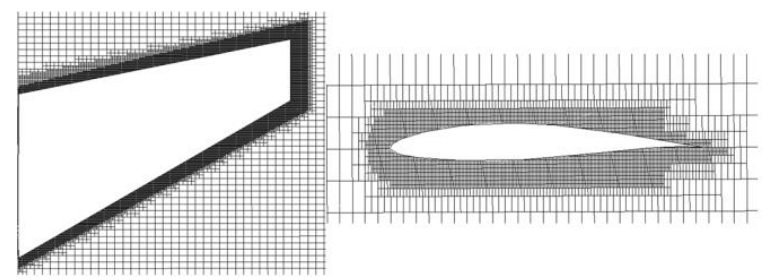

Şekil 13: Kanat ve Airfoil etrafındaki lokal ilk çözüm ağ1

FloEFD çözüm sırasında çözüm ağını yenileyebilme kapasitesine sahiptir. Çözüm ağı, akışın fiziksel ve kimyasal parametrelerin değiştiği alanlarda sıklaştırılırken, akış parametrelerinin sabit kaldığ yerlerde otomatik olarak seyrekleştirilir. (Mentor Graphics, 2010) daha iyi çözüm elde edebilmek için hem lokal çözüm ağını hem de çözüm sırasında çözüm ağ1 arttırıc1 sistemin(SAR) beraber kullanılmasını önermiştir. SAR sistemi, çözüm içerisinde $0,7,1,5$ ve 2,2 "travel" noktalarında olmak üzere üç sefer harekete geçmek üzere programlanmıştır.

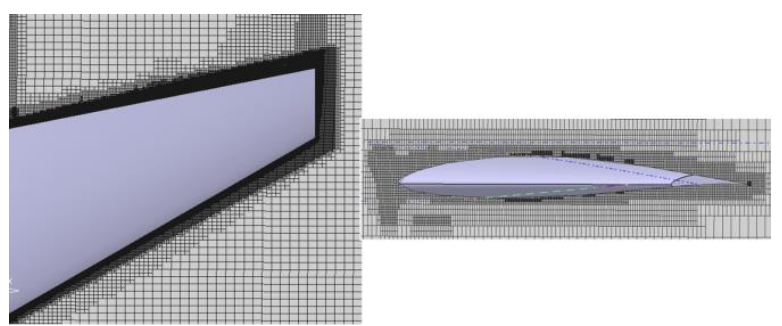

Şekil 14: Kanat ve Airfoil etrafindaki lokal son çözüm ağ1

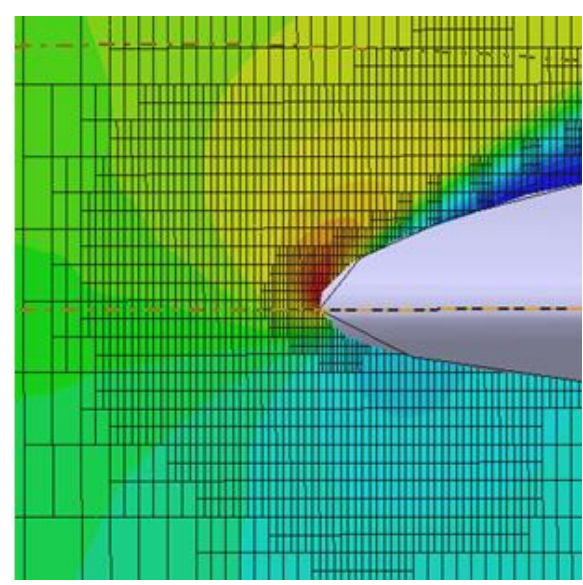

Şekil 15: $16^{0}$ hücum açısı çözümü sırasında Airfoil hücum kenarında çözüm adaptasyonlu çözüm ağ1 iyileme örneği

HAD analizlerin ilk aşamasında Kuyruk kısmı sabit tutularak yüksek-kanat, orta-kanat ve alçak-kanat çeşitleri karşılaştırılmıştır. Yani, Karşılaştırılan üç konfigürasyon Yüksek kanat-T kuyruk, Orta kanat-T kuyruk ve Alçak kanat-T kuyruk modelleridir. Aşağıdaki şekillerde CL, CD ve L/D vs hücum açısı grafikleri verilmektedir.

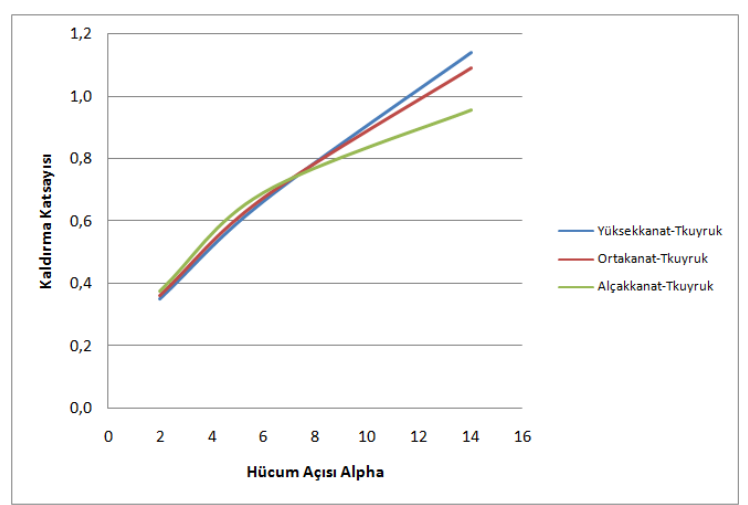

Şekil 16: Kaldırma katsayısının hücum açısına göre değişimi Yüksek kanat, orta kanat ve alçak kanat

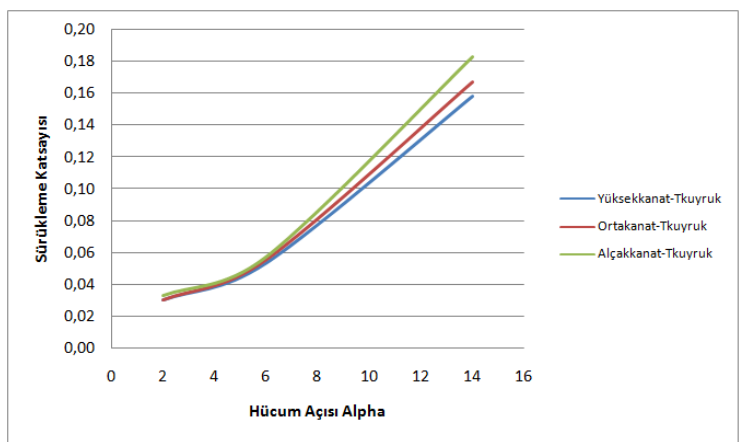

Şekil 17: Sürükleme katsayısının hücum açısına göre değişimi Yüksek kanat, orta kanat ve alçak kanat

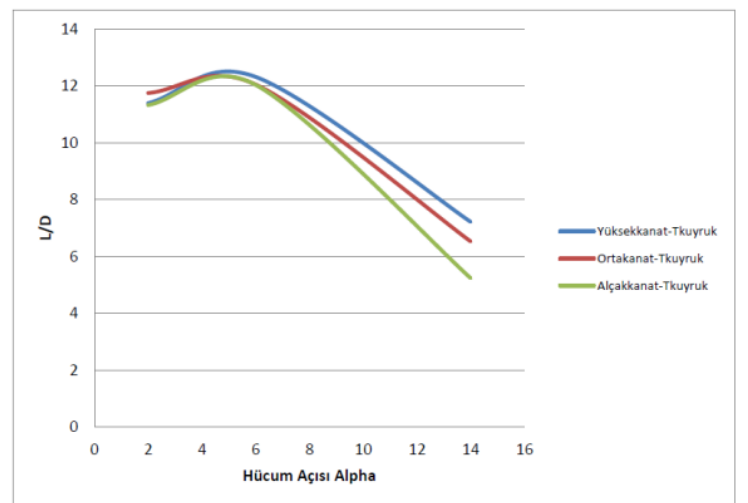

Şekil 18: L/D parametresinin hücum açısına göre değişimi Yüksek kanat, orta kanat ve alçak kanat

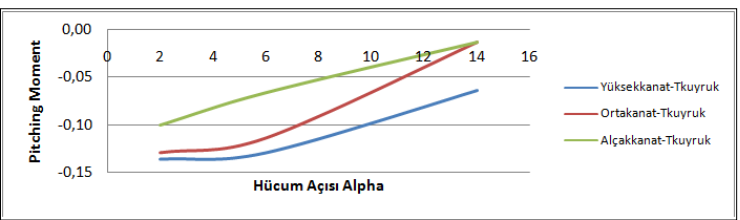


Şekil 19: Yunuslama Moment katsayısının hücum açısına göre değişimi Yüksek kanat, orta kanat ve alçak kanat

Kaldırma ve sürükleme katsayıları ve L/D parametrelerin hücum açılarına göre değişim grafikleri incelendiğinde özellikle orta ve yüksek hücum açılarında yüksek-kanat modeli en düşük sürükleme katsayısını, en yüksek L/D performansını verdiği görülmüştür. $\mathrm{Bu}$ sebeple yüksek-kanat modeli seçilmiştir.

Yüksek kanat seçimi yapıldıktan sonra kanat pozisyonu sabit tutulmuş ve kuyruk dikey pozisyonu değiştirilmiştir. Kaldırma ve sürükleme katsayıları ve yunuslama momenti katsayılarının hücum açısı ile değişimi ile, kaldırmanın sürüklemeye oranı grafikleri aşağıdaki şekillerde verilmiştir.

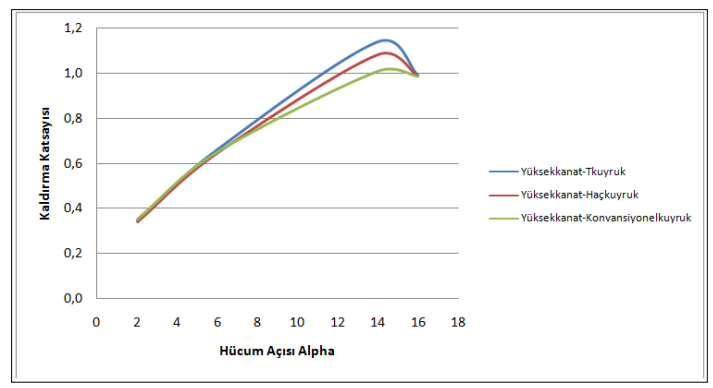

Şekil 20: Kaldırma katsayısının hücum açısına göre değişimi T-kuyruk, haç kuyruk ve konvansiyonel kuyruk

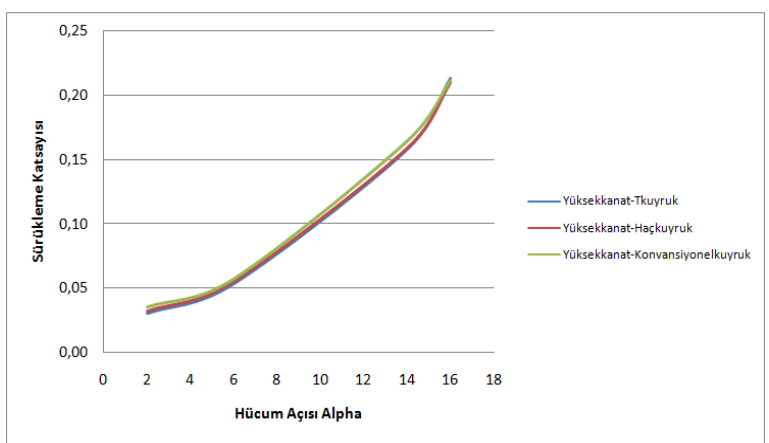

Şekil 21: Sürükleme katsayısının hücum açısına göre değişimi T-kuyruk, haç-kuyruk ve konvansiyonelkuyruk

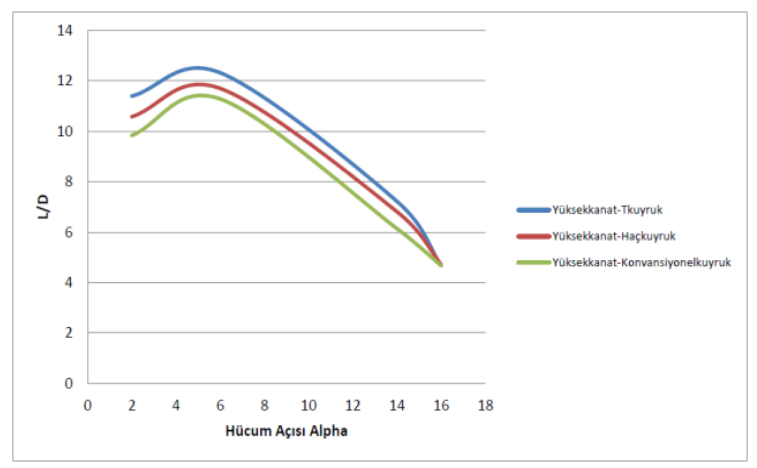

Şekil 22: L/D değerinin hücum açısına göre değişimi T-kuyruk, haç-kuyruk ve konvansiyonel-kuyruk

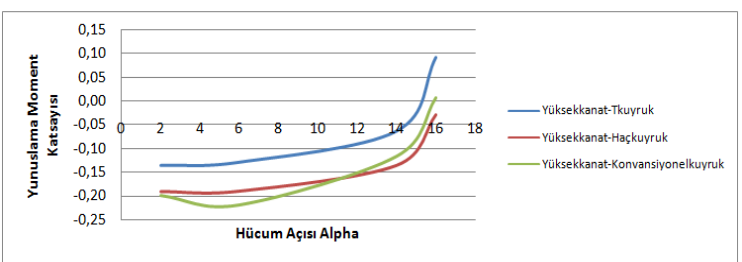

Şekil 23: Yunuslama Moment katsayısının hücum açısına göre değişimi T-kuyruk, haç-kuyruk ve konvansiyonel-kuyruk

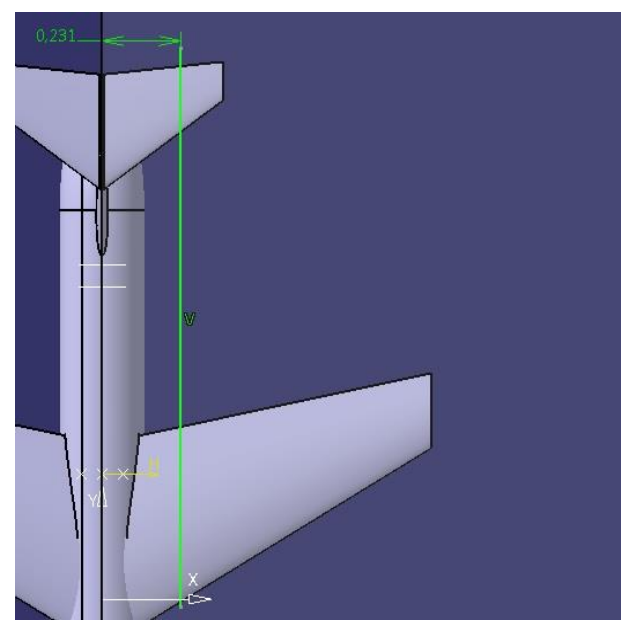

Şekil 24: Kanat Açıklığı yönünde 0,231 m Dikey Kesit

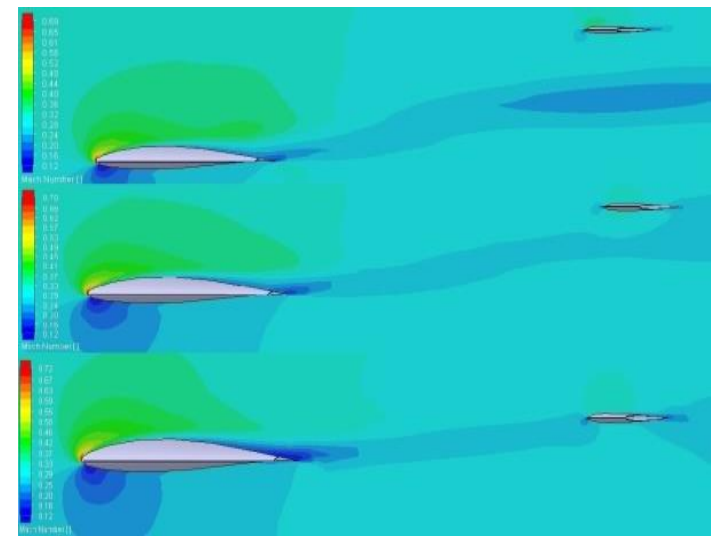

Şekil 25: 16 derece hücum açısında Mach sayısının kontur kesitlerinin farklı kuyruk çeşitleri için gösterimi. Yukarıdan aşağıya: T-kuyruk, Haç-kuyruk ve konvansiyonel-kuyruk.

Kanadın kuyruğa etkisini ölçmek maksadı ile 16 derece hücum açısında kanat stall durumunda iken dikey kesit alınmıştır. Dikey kesit bölgesi Şekil 24' de gösterilmiştir.

HAD analizleri sonucunda Yüksek kanat-T kuyruk konfigürasyonunun yüksek hücum açılarında en düşük sürükleme katsayısı ürettiği ve en yüksek L/D değerini verdiği tespit edilmiştir. Kanat uçlarından başlayan stall durumunun 16 derece hücum açısında merkez hattından 0,231 m açı̆̆ına ulaşmadığı gözlemlenmiștir. Bununla beraber 16 derece hücum açısında yüksek kanattan en az etkilenen kuyruk tipi T-kuyruk olarak belirlenmiştir. Bir sonraki tabloda İHA'nın seyir koşulları için teorik değerleri ile HAD analizlerinin karşılaştırılmasını içermektedir. 
Tablo 5: Yüksek Hızlı Sahte Hedef IHHA HAD Sonuçları

\begin{tabular}{|c|c|c|}
\hline Parametre: & $\begin{array}{c}\text { Ana } \\
\text { Tasarım } \\
\text { (Teorik) }\end{array}$ & $\begin{array}{c}\text { Yüksek } \\
\text { Kanat- } \\
\text { Tkuyruk } \\
\text { (HAD) } 0,3 \mathrm{M} \\
\text { Seyir }\end{array}$ \\
\hline $\begin{array}{c}\mathrm{C}_{\mathrm{LDDsign}(\text { teori) }} \\
\mathrm{C}_{\mathrm{LSeyir}(H A D)}\end{array}$ & 0,242 & 0,187 \\
\hline $\mathrm{C}_{\mathrm{D} \text { seyir }}$ & 0,024 & 0,0239 \\
\hline $\mathrm{C}_{\mathrm{L} \text { Max }}$ & 1,09 & 1,14 \\
\hline $\mathrm{L}_{\mathrm{D}} \mathrm{D}_{\text {Seyir }}$ & 9,86 & 7,84 \\
\hline $\mathrm{L} / \mathrm{D}_{\max }$ & 12,72 & 12,61 \\
\hline
\end{tabular}

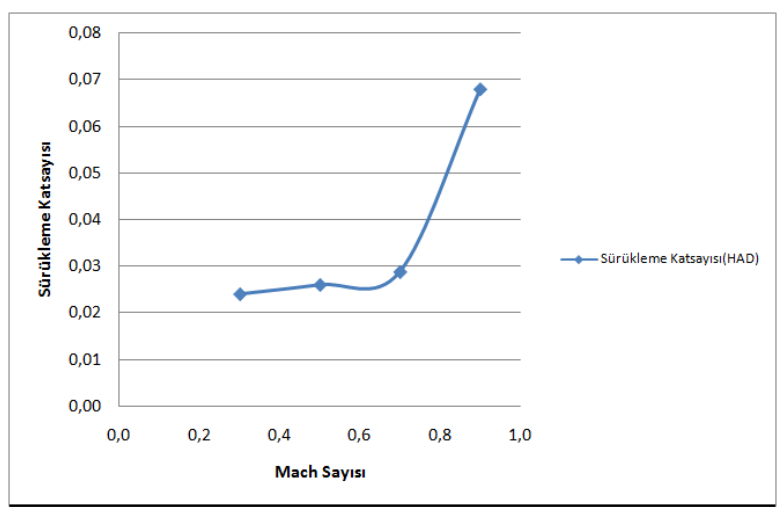

Şekil 26: Sürükleme katsayısının Mach sayısına göre değişimi

Şekil 26 ya göre uçağın sürükleme katsayısı 0,7 mach sayısında kayda değer bir yükselme göstermemiştir. Sürükleme katsayısının $0,9 \mathrm{M}$ da yükselmesi, şok dalgasının bu hızda etkili olduğunu gösterir.

Uçağın çıkabileceği maksimum hız, uçağın itki kuvveti gereksinimi ile doğru orantılıdır ve itki kuvveti gereksinimi de uçağın ürettiği sürükleme katsayısı ile doğru orantılıdır. Uçak için gereken itki kuvveti aşağıdaki denklemde verilmiştir (Anderson, 1999).

$$
\mathrm{T}_{\mathrm{R}}=\mathrm{q} * \mathrm{~S} * \mathrm{C}_{\mathrm{D}}
$$

HAD analizleri sonrasında uçağın farklı hızlarda uçarken ürettiği sürükleme katsayıları kullanılarak aşağıdaki şekil elde edilmiştir. Şekilde gösterilen mevcut itki, uçağa motor takıldığındaki itkidir.

\subsection{Maksimum Hız HAD Analizleri}

Tasarlanan İHA'nın, 0,7 Mach sayısında uçabilmesi hedeflenmiş̧tir. Hedef İHA'nın bu hızda uçabildiğini görebilmek için HAD simülasyonu yapılmıştır. 0,7 Mach sayısı uçaklar için transonik bir hızdır. Uçak, bu hızda uçarken kanadın üst yüzeylerinde akış hızının 1 Mach' in üzerine çıkarak kanatlarda şok dalgası oluşma tehlikesi bulunmaktadır. Uçağın kanatlarının üst yüzeyinde oluşan şok dalgaları, uçağın kanadında oluşmuş olan sınır tabakası ile etkileşime girerek akışın kanatlardan kopmasına neden olmaktadır. Şok dalgası oluştuğu zaman, uçağın sürükleme katsayısına şok dalgası sürükleme katsayısı bileşeni eklenir ve uçağın ürettiği sürükleme katsayısı katlanarak artar. Şekil 26 uçağın farklı hızlardaki ürettiği sürükleme katsayılarını göstermektedir.

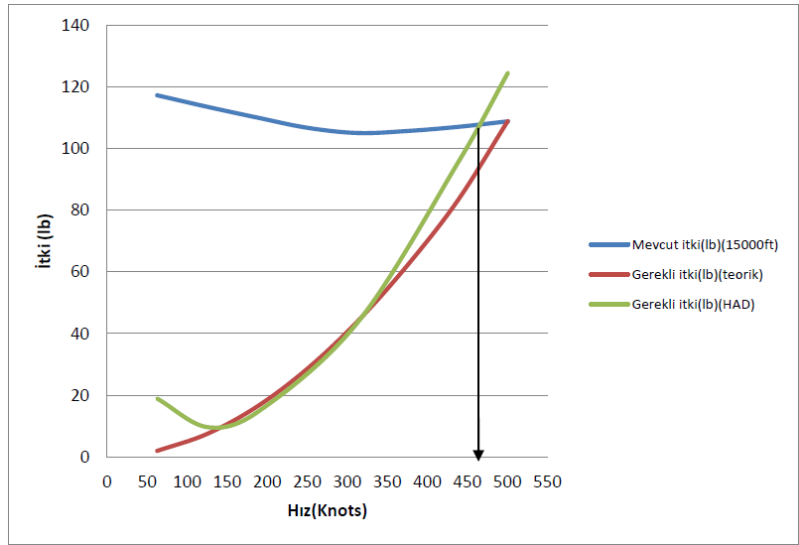

Şekil 27: Mevcut itki ve Gerekli itkinin hıza bağlı grafiği

0,7 Mach hızında, farklı hücum açılarında HAD analizleri sonucunda İHA'nın verdiği sürükleme katsayılarından yola çıkılarak bulunan gerekli itki eğrilerine bakıldığında, uçağın 450 knot hıza ulaşabildiği görülmüştür.

Uçağın 0,7 mach hızında 0 derece hücum açısında uçarken kanat yüzeyindeki hava akış hızını kontrol edebilmek için merkez hattından kanat açıklı̆̆ı yönünde üç farklı uzaklıktan kesit alınmıştır. Bu uzaklıklar, kuyruk aerodinamik merkez noktasının bulunduğu $0,231 \mathrm{~m}$, kanat aerodinamik merkez noktasının bulunduğu $0,417 \mathrm{~m}$ ve kanat ucuna yakın bir düzlem olan $0,8 \mathrm{~m}$ olarak seçilmiş̧ir. Bu noktalar aşağıdaki şekilde gösterilmiştir.

Maksimum hız için yapılan HAD analizi sonucunda tasarlanan İHA 0 derece hücum açısında uçarken kanat üzerindeki akış hızının 1 Mach'ı aşmadı̆̆ı gözlemlenmiştir. Tespit edilen kanat üzeri akış hızları 0,94 ile 0,96 Mach sayısı dolaylarında seyretmektedir. 


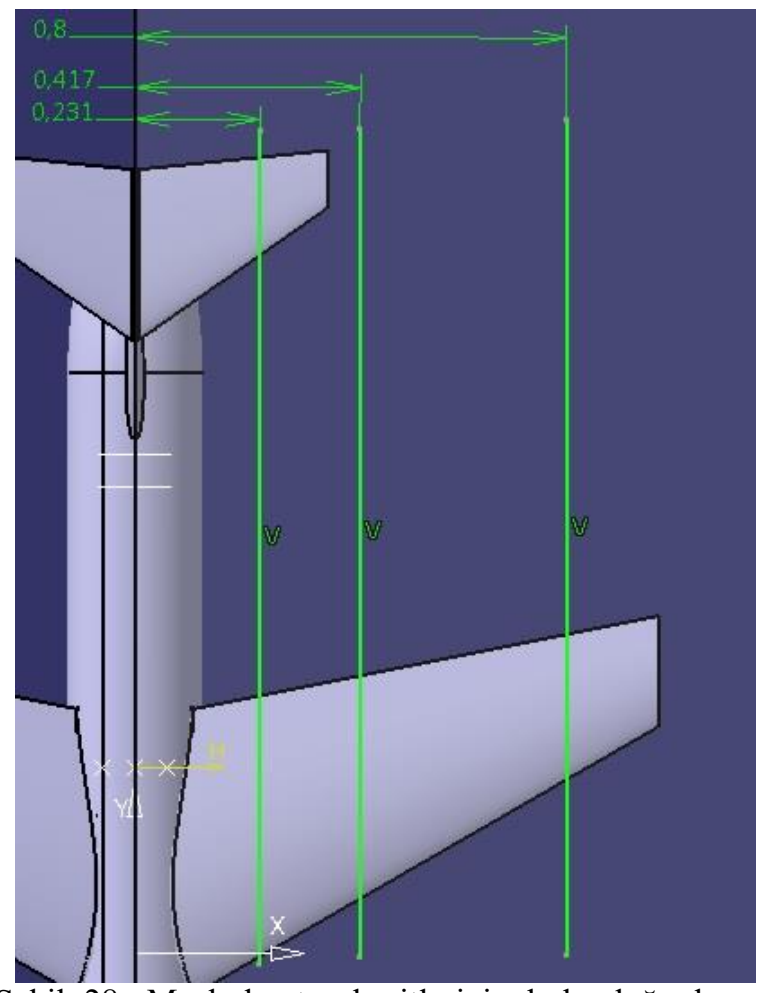

Şekil 28: Mach kontur kesitlerinin bulunduğu kanat açıklığı yönündeki düzlemler

\section{0,231 m kanat açıklığı yönü}

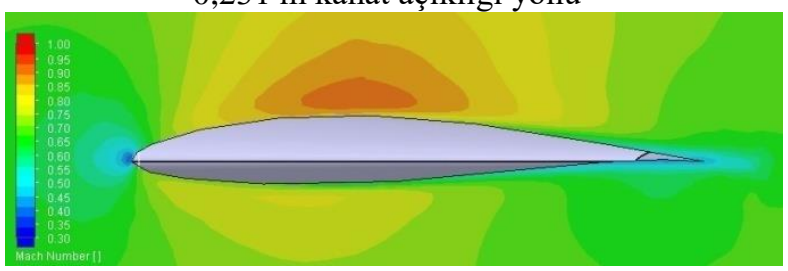

0,417 m kanat açıklığı yönü

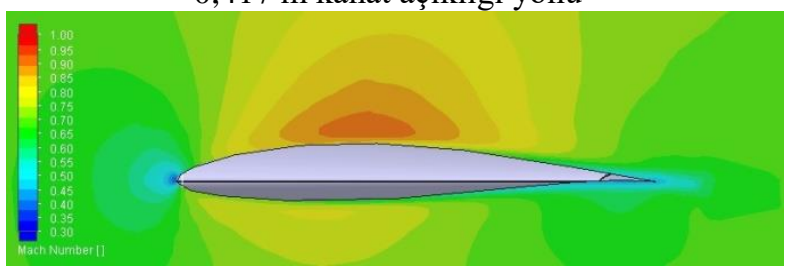

0,8 m kanat açıklığı yönü

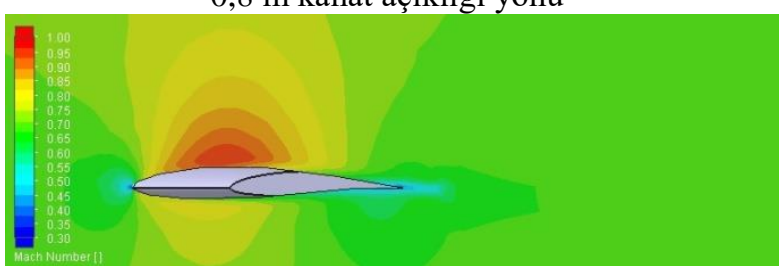

Şekil 29: 0,7 M hızında 0 Derece Hücum Açısında Seyir Halinde İHA Kanat Üzeri Mach Sayısı Kontur Çizimleri

\section{SONUÇ}

$\mathrm{Bu}$ çalışmada yüksek hızlı hedef İHA tasarımı yapılmıştır. Tasarımın gereksinimleri daha önce tasarımı yapılmış hedef İHA tecrübelerinden faydalanılarak hazırlanmıştır. Bu dizayn için $231 \mathrm{~m} / \mathrm{s}$ maksimum hız, 1 saat dayanım süresi ve $100 \mathrm{~km}$ menzil hedeflenmiştir. Tasarlanan İHA geometrik ve aerodinamik parametreleri, daha önce tasarlanmış başarılı İHA istatistikleri kullanılarak ve tekrarlanan uçak dizayn hesapları ile ortaya konmuştur. Hedef uçak için gereken jet motoru dikkatle seçilmiş ve motorun teknik resmi kullanılarak 3 boyutlu bilgisayar destekli tasarım programı olan CATİA-v5 yazılımında çizimi yapılmış ve uçağın gövdesine entegrasyonu yapılmıştır. Temel tasarımda kuyruk ve kanat dikey pozisyonu olarak Orta-kanat ve T-kuyruk konfigürasyonu seçilmiştir. Bu konfigürasyonlar arasındaki aerodinamik performans farklarını karşılaştırabilmek ve en uygun kanat ve kuyruk pozisyonlarını belirleyebilmek amacı ile farklı kanat ve kuyruk dikey pozisyonlarının olduğu sekiz farklı konfigürasyonun dizaynı yapılmıştır ve konfigürasyon matrisi oluşturulmuştur. $\mathrm{Bu}$ konfigürasyonların arasındaki farkı ölçebilmek için CAD yazılımlarına entegre çalışan FloEFD HAD yazılımı tercih edilmiştir. Aerodinamik performans testleri $15000 \mathrm{ft}$ irtifa şartlarında 2, 6, 14 ve 16 derece hücum açlarında yapılmıştır. HAD analizleri neticesinde YüksekKanat-Tkuyruk dizaynının en iyi aerodinamik performansı verdiği tespit edilmiştir.

Tasarlanan İHA'nın, çıkması istenen 0,7 Mach sayısında da HAD analizleri yapılmıştır. Bu analizlerde uçağın farklı hızlarda ürettiği sürükleme katsayısı ve itki gereksinimleri incelenmiş, uçağın var olan Nike turbojet motoru ile maksimum hızda uçuşunu sürdürebileceği öngörülmüştür. Uçağın maksimum hızda seyrederken kanat üzerindeki farklı kesitlerden hava akışı incelenmiş ve kanat üzeri akışın süpersonik hıza çıkmadığı gözlemlenmiştir.

Sonuç olarak, uçak dizaynı sürecinde, uçağın verdiği aerodinamik performansın anlaşılabilmesi için prototipler üretilip bu prototiplerin rüzgâr tünelinde test edilmesi gerekmektedir. Rüzgâr tüneli testleri gerçeğe en yakın aerodinamik performansı verdiği için şüphesiz vazgeçilmezdir. Fakat, her bir konfigürasyon için prototip üretip rüzgâr tünelinde testini yapmak hem çok fazla zaman tüketimi hem de çok maliyetlidir. $\mathrm{Bu}$ çalışmada HAD yazılımı olan FloEFD, hem farklı konfigürasyonların karşılaştırılmasında rol oynamış hem de uçağın limit hızlarında nasıl tepki verdiğinin anlaşılabilmesini sağlamıştır.

\section{KAYNAKLAR}

AMT Nederlands B.V. (2012), Description of the AMT Nederlands Nike Gasturbine,www.amtjets.com, Spaarpot 34 NL-5667 KX Geldrop, Holland, NEDERLANDS.

Anderson, John D. (1999), “Aircraft Performance and Design, Mc-Graw-Hill. University of Maryland

BSK Defence S.A. (2016), URL: http://www.redstar.gr/Foto_red/Eng/HAF/BSK_def ense/Yperion.html [Son ziyaret tarihi Mart 2016]

BSK Defence S.A. (2016), URL: http://www.redstar.gr/Foto_red/Eng/HAF/BSK_def ense/Nemisis.html [Son ziyaret tarihi Mart 2016]

Composite Engineering, Inc. ,(2016), URL: www.kratosusd.com,[Son ziyaret tarihi Nisan 2016].

Meggitt Defence Systems Ltd, (2016), URL: https://meggitttargetsystems.com/static/media/files/ Banshee_Twin_Jet_2015.pdf [Son ziyaret tarihi Nisan 2016].

Mentor Graphics Corporation, (2010) "FloEFD Aerospace Validation and Test-Cases," 
www.mentor.com,8005 S.W. Boekman Road, Wilsonwille, Oregon 97070-7777

Mentor Graphics Corporation, (2014) "NASA Common Research Model Aerodynamics," www.mentor.com,8005 S.W. Boekman Road, Wilsonwille, Oregon 97070-7777

Raymer, D.P. (2012), “Aircraft Design: A Conceptual Approach(5th ed.)," Washington: American Institute of Aeronautics and Astronautics.

Sadraey, Mohammad H. (2013), "Aircraft Design:A Systems Engineering Approach”, Daniel Webster College, New Hampshire, USA.

Türk Havacılık ve Uzay Sanayi A.Ş, (2016), URL: www.tai.com.tr,[Son ziyaret tarihi Nisan 2016]. 